The difficulty that researchers face in answering these questions is gaining access to convicted drinking drivers. Before drink-driving legislation was widespread the central problems were tackled indirectly. Glatt found that most inpatients in an alcohol treatment unit admitted to driving while intoxicated. ${ }^{2}$ Using prevalence figures from Sweden and Canada, he inferred that alcoholics were about $10 \%$ of those arrested for drink-driving offences. Selzer in the United States in 1963 studied referrals from a judge and produced the more alarming figure of $57 \%{ }^{3}$

Two years later the Grand Rapids study established the supreme importance of alcohol as a cause of fatal traffic accidents and led to legislation in many countries whereby a blood alcohol concentration above a certain limit in a driver was an offence in itself. $^{4}$ With a dramatic increase in convictions and the disease model of alcoholism in its heyday there was a demand for rehabilitation of the driver in addition to legal penalties. Rehabilitation programmes are now operating in all the American states and are widespread in New Zealand, Australia, Scandinavia, Holland, West Germany, and Switzerland. ${ }^{5}$ They also exist to a lesser extent in France. These programmes have generated research mainly concerned with their own efficacy but have also provided answers to the questions posed above. Whereas Selzer's original study was of 67 drivers, Fine and Scoles looked 14 years later at 2300 people in rehabilitation programmes and came to similar conclusions on the prevalence of alcohol dependence. ${ }^{6}$

In Britain the 1967 legislation did not produce the same spark. We have no official policy on rehabilitation, although some local projects are promoted by magistrates and the probation service. ${ }^{7}$ There is thus little opportunity for research, and that which is done is due to the efforts of groups such as the Tayside Safe Driving Project. For the most part in Britain the question of prevalence of alcohol related problems in drunk drivers is not only unanswered but unasked. The drink-driving population remains inaccessible.

Even when accessible the subjects are not necessarily scrutable. The mainstays in case finding of those in the community with alcohol problems are questionnaires, but in a population described by Selzer as "not overtly cooperative" their use must be open to doubt. Dunbar in his samples of recently arrested drivers used serum $\gamma$-glutamyltransferase activity as an index of problem drinking. In one such sample he found that almost a third of those arrested for drinkdriving offences had raised serum $\gamma$-glutamyltransferase activity and that most of these had similar rises five to nine months later. ${ }^{8}$ Given the limited sensitivity of the test this is likely to be an underestimate of the prevalence of those who were problem drinkers. A person already convicted and taking part in rehabilitation is more likely to be honest about his drinking, and researchers using the Michigan alcoholism screening test (MAST) in such populations to screen for problem drinkers find that more than four fifths score positively. ${ }^{90}$ Even allowing for false positives when the test is used with drink-driving offenders, ${ }^{11}$ these results provide an ominous rider to Dunbar's figures. There is currently no possibility of trying to replicate them in Britain.

While rehabilitation programmes enable the subject population to be scrutinised, some doubt both the forensic and clinical benefits of the programmes. Most reviewers do, however, think that they have some value. ${ }^{112}$ There would therefore seem to be no excuse for remaining aloof; effective programmes will come only from refining those already operating. In this respect Britain is already behind most other countries. It may be unrealistic to suppose that clinical and forensic aims can always be dovetailed, but ultimately the costs of both services are borne by the same exchequer. Screening and rehabilitation of drink-driving offenders may pay dividends in either sphere. Currently, however, the convicted drink-driving offender has no incentive to face up to his problem drinking, as Dunbar's follow up figures show. The government is otherwise engaged in an education campaign on drinking and driving that is of questionable efficacy without adequate enforcement. The judiciary and police are embroiled in "back extrapolation" of blood alcohol concentrations, an issue which will complicate rather than simplify prosecution. Consequently the issue of what to learn from and what to do with those drivers who are caught and convicted remains neglected. We think that this is precisely the kind of issue that might well be considered by the new interministerial group on alcohol abuse.

ANThony ClaRe

Professor of psychological medicine M BRISTOW Research registrar

Department of Psychological Medicine, St Bartholomew's Hospital Medical College, London EC1A 7BE

1 Alcohol Concern. The Drinking revolution. London: Alcohol Concern, 1987.

la Working Group on Young People and Alcohol. Report. London: Home Office, 1987.

2 Glatt M. Alcoholism in impaired and drunken driving. Lancet 1964;i:162.

3 Selzer W. Alcoholism, mental illness and the drunken driver. Am J Psychiatry 1963;120:326-31. 4 Borkenstein RF, Crowther RP, Shumate WB, Zeil WB, Zylman R. The role of the drinking driver in traffic accidents. Indiana: University of Indiana. 1964.

5 Waller P. Licensing and other controls of the drinking driver. Stud Alcohol 1985;July (suppl 10): $156-60 \mathrm{~S}$.

6 Fine EW, Scoles $P$. Secondary prevention of alcoholism using a population of offenders arrested for driving while intoxicated. Ann NYAcad Sci 1976;273:637-45.

7 Martin JP. A course for drivers convicted of drink/driving. F ustice of the Peace 1986;March:182-4. 8 Dunbar J, Martin BT, Devgun MS, Hagart J, Ogston SA. Problem drinking among drunk drivers. BrMed F 1983;286:1319-22. (Tayside Safe Driving Project.)

9 Brown RA. Use of the M.A.S.T. with hospitalized alcoholics, psychiatric patients, drinking drivers and social drinkers. Am $\mathcal{f}$ Drug Alcohol Abuse 1979;6:1375-81.

10 Zung B. Correlates of the M.A.S.T. among DWI offenders. F Clin Psychol 1984;40:607-12.

11 Mann R, Leigh G, Vingilis ER, de Genova K. A critical review of the effectiveness of drink driver rehabilitation programmes. Accident analysis and Prevention 1983;15:441-61.

12 Kunkel E. Driver improvement courses for drink drivers reconsidered. Accident Analysis and Prevention 1983;15:429-39.

\section{Preventing lung cancer}

Treatment of lung cancer is essentially palliative- $90 \%$ of patients die. Prevention is thus vitally important and must mostly be aimed at reducing the numbers who smoke. The signs are not all good: smoking among adults has declined, but more among men than women. ${ }^{1}$ Thus, although the death rate from lung cancer among men has declined by $5 \%$ since a peak in 1980, among women it has increased by $21 \%$. Now women aged 16-19 smoke more than men of the same age, and between 1982 and 1984 the prevalence of smoking rose in this group. ${ }^{12}$ Against this background the Marie Curie Memorial Foundation has just held a meeting on preventing lung cancer that concentrated on health education about smoking in schools and passive smoking. The timing was fortuitous because government legislation may well follow the forthcoming report by Sir Peter Froggett's committee on tobacco and health. 
Dr Anne Charlton reported on a survey of 15000 schoolchildren aged 9-19 in Cumbria and Tyne and Wear. ${ }^{37}$ She found that most experimentation with cigarettes starts at between 9 and 11, regular smoking usually starts at about 12 or 13 , and children are more likely to smoke if their parents do so. Other factors that increase the chances that children will smoke are parental approval; brothers and sisters, friends, and teachers who smoke; advertising; and beliefs about the perceived "benefits" of smoking. Similar results were reported in a study from Derbyshire by Holland and his group, who concluded that any health education programme must start before 14 to stand a chance of success. ${ }^{8}$

Guidelines for health education on smoking have been developed based on data from these and similar studies, and Dr Charlton is currently assessing the impact of a new education programme on smoking. ${ }^{9}$ The Brigantia smoking prevention programme employs a step by step process that starts at 9 and continues until 17 and encourages the children to share and discuss the information with their parents. Preliminary data suggest that this approach can decrease smoking among boys and their fathers but has less effect in girls and their fathers. Mothers, disturbingly, showed no swing away from smoking.

Any effects of passive smoking are particularly important as even a small increase in risk of lung cancer or other diseases will affect most of the population. Wald et al have concluded from a recent meta-analysis that people exposed to passive smoking have a small but definite increased risk of developing lung cancer.$^{10} \mathrm{In}$ addition, the children of smokers have a lower weight at birth, show poorer growth, and are more prone to respiratory problems. ${ }^{112}$ Though changes in smoking policies in British workplaces have been slow, the Health Education Authority has just produced a booklet, Smoking Policies at Work, and there appears to be public support for change. In a MORI poll of 854 workers in 1986 only $14 \%$ believed that smoking should be allowed in all workplace areas, while $80 \%$ would have agreed to some degree of restriction. Any changes should be planned and include participation and agreement from staff at all stages of their development. Such a policy has proved successful in several British companies, and pressure for change in others is likely to grow. Further government legislation on smoking in public places is contemplated. In 1985 the London Underground introduced a smoking ban, a change which prodyced little resistance from the travelling public. Clearly some forms of legislation are likely to be acceptable to the public.

\section{J Williams} Senior lecturer

CRC Wessex Regional Medical Oncology Unit, Southampton SO9 4XY

\footnotetext{
1 Anonymous. Cigarette smoking: 1972 to 1984. London: Office of Population Censuses and Surveys, 1985.

2 Goddard E, Ikin C. Smoking among secondary school children in 1986. London: Office of Population Censuses and Surveys, 1986.

3 Charlton A. The Brigantia smoking survey: a general review. Public education about cancer. UICC Technical Report Series 1984;77:92-102.

4 Charlton A. Teachers' smoking habits. Community Med 1984;6:273-80.

5 Charlton A. Children who smoke. Health at School 1986;1:125-7.

6 Charlton A. Children's advertisements-awareness related to their views on smoking. Health Education fournal 1986;45:75-8.

7 Charlton A. Smoking and weight control in teenagers. Public Health 1984;98:278-81.

8 Murray M, Swan AB, Bewley BR, et al. The development of smoking during adolescence. The MRC Derbyshire smoking study. Int $\mathcal{F}$ Epidemiol 1983;12:185-92.

9 Charlton A. Evaluation of a family-linked smoking programme in primary schools. Health Education fournal 1986;45:140-4.

10 Wald NJ, Nanchahal K, Thompson SG, Cuckle HS. Does breathing other people's tobacco smoke cause lung cancer? BrMed f 1986;293:1217-22.

11 Charlton A. Children's coughs related to parental smoking. Br Med f 1984;288:1647-9.

12 United States Surgeon General. Health consequences of involuntary smoking. Washington, DC: Government Printing Office 1986.
}

\section{Management of retinal vein occlusion}

Occlusion in the retinal venous system is a common cause of visual loss in the middle aged in the United Kingdom. ${ }^{1}$ Occlusion of both the central and the branch veins reduces the visual acuity, but the severity of this varies. Even when the central retinal vein is occluded, however, the visual loss occurs slowly, over hours or even days, so that the patient may only inadvertently become aware of the deficit, for example, when occluding the unaffected eye. New blood vessels may develop in the iris in $20-50 \%$ of patients with central retinal vein occlusion with the invariable development of neovascular glaucoma. Until the mid-1970s retinal vein occlusion and its complications (which also include macular oedema) were regarded as untreatable. Nevertheless, the encouraging recent results obtained from treatment with laser photocoagulation has prompted an aggressive approach towards neovascularisation. Given, moreover, that the mortality rate in patients with retinal vein occlusion from cardiovascular disease (particularly stroke) is double the national average and that $10-15 \%$ of patients develop a further retinal venous occlusive event, often resulting in blindness, there is also now an emphasis on a combined prophylactic approach by both a physician and ophthalmologist. ${ }^{23}$

We still do not know what causes retinal vein occlusion, though recent data suggest that there are several factors. Histological studies support the concept that it is due to damage to the endothelium, with proliferation of the endothelial cells the major primary histological change; this may be associated with degeneration, phlebosclerosis, or secondary intramural thrombus formation. ${ }^{45}$ Conditions that predispose to retinal vein occlusion include vasculitis, chronic glaucoma, diabetes mellitus, hyperviscosity syndromes, and use of contraceptives containing oestrogen. ${ }^{6-8}$ Nevertheless, these factors are present in only a few patients, and hypertension (often poorly controlled) is the most frequently associated condition, being present in half the middle aged patients. ${ }^{9}$ Hyperlipidaemia is found in just under a third of middle aged patients and is the predominant condition found in young patients, indicating that it may play an important part. ${ }^{39}$ Other abnormal test results include raised concentrations of $C$ reactive protein and immunoglobulin A, as well as an increased plasma viscosity and erythrocyte sedimentation rate. ${ }^{111}$ Abnormal platelet aggregability and in vivo platelet function have been reported even in patients with no other underlying disease, suggesting that platelet aggregation might be an important sequel to endothelial swelling, thus leading to the occlusion..$^{12} 13$ Statistically, also, more of these patients smoke and drink than people without retinal vein occlusion. ${ }^{7914}$

Clinical management, then, consists of treatment of the ophthalmic complications, together with systemic investigation and medical treatment of any abnormalities that are found. Retinal photocoagulation may inhibit the formation of new blood vessels or bring about regression, thereby preventing vitreous haemorrhage. In the central form treatment of the ischaemic retina may additionally inhibit the development of rubeosis of the iris, so preventing neovascular glaucoma. ${ }^{15-17}$ Although macular oedema after occlusion of the branch veins may benefit from focal laser treatment, after occlusion of the central vein the results are disappointing. ${ }^{18}$ 